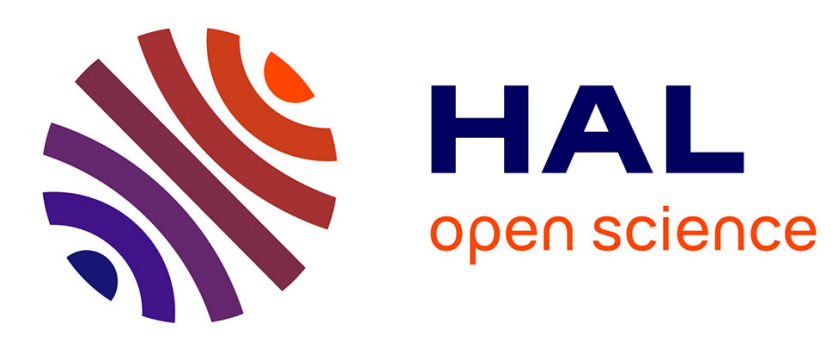

\title{
Catalytic reduction of TFSI-containing ionic liquid in the presence of lithium cations
}

Michal Tulodziecki, Jean-marie Tarascon, Pierre-Louis Taberna, Claude Guéry

\section{To cite this version:}

Michal Tulodziecki, Jean-marie Tarascon, Pierre-Louis Taberna, Claude Guéry. Catalytic reduction of TFSI-containing ionic liquid in the presence of lithium cations. Electrochemistry Communications, 2017, vol. 77, pp. 128-132. 10.1016/j.elecom.2017.02.014 . hal-01671204

\section{HAL Id: hal-01671204 https://hal.science/hal-01671204}

Submitted on 22 Dec 2017

HAL is a multi-disciplinary open access archive for the deposit and dissemination of scientific research documents, whether they are published or not. The documents may come from teaching and research institutions in France or abroad, or from public or private research centers.
L'archive ouverte pluridisciplinaire HAL, est destinée au dépôt et à la diffusion de documents scientifiques de niveau recherche, publiés ou non, émanant des établissements d'enseignement et de recherche français ou étrangers, des laboratoires publics ou privés. 


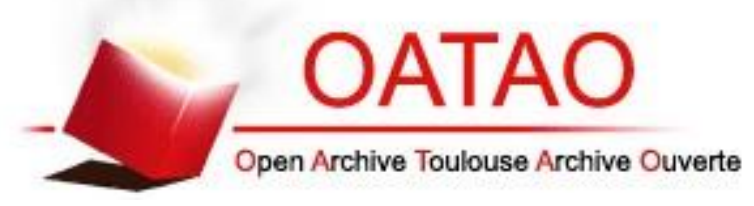

\section{Open Archive TOULOUSE Archive Ouverte (OATAO)}

OATAO is an open access repository that collects the work of Toulouse researchers and makes it freely available over the web where possible.

This is an author-deposited version published in : http://oatao.univ-toulouse.fr/ Eprints ID : 19357

To link to this article : DOI: 10.1016/j.elecom.2017.02.014

URL : http://dx.doi.org/10.1016/j.elecom.2017.02.014

To cite this version : Tułodziecki, Michal and Tarascon, Jean-Marie and Taberna, Pierre-Louis and Guéry, Claude Catalytic reduction of TFSIcontaining ionic liquid in the presence of lithium cations. (2017) Electrochemistry Communications, vol. 77. pp. 128-132. ISSN 1388-2481

Any correspondence concerning this service should be sent to the repository administrator: staff-oatao@ listes-diff.inp-toulouse.fr 


\title{
Catalytic reduction of TFSI-containing ionic liquid in the presence of lithium cations
}

\author{
M. Tułodziecki ${ }^{\text {a,b }}$, J.-M. Tarascon ${ }^{\text {c,d }}$, P.-L. Taberna ${ }^{\text {e,f }}$, C. Guéry ${ }^{\text {a,b,* }}$ \\ a Laboratoire de Réactivité et Chimie des Solides, UMR CNRS 7314, UFR des Sciences, 33 rue saint Leu, 80039 Amiens Cedex, France \\ ${ }^{\mathrm{b}}$ ALISTORE European Research Institute, FR CNRS 3104, UFR des Sciences, 33 rue Saint Leu, 80039 Amiens Cedex, France \\ c College de France, 11 Rue, Place Marcelin Berthelot, 75231 Paris, France \\ d Reseau sur le Stockage Electrochimique de l'Energie (RS2E), FR CNRS 3459, France \\ e CIRIMAT, Université de Toulouse, UMR CNRS 5085, INPT, UPS, France \\ ${ }^{\mathrm{f}}$ ALISTORE European Research Institute, FR CNRS 3104, 118 route de Narbonne, 31062 Toulouse cedex 9, France
}

Keywords:

Double layer

Ionic liquids

SEI

EQCM

Lithium

XPS

\begin{abstract}
A B S T R A C T
The influence of the electrochemical double layer (EDL) structure on the electrochemical processes in ionic liquids is an intriguing subject. The complex layered structure of the EDL and its restructuring have been shown to strongly affect metal deposit morphology and electrochemical reaction kinetics. In this work, we demonstrate that the breakdown of an ionic liquid containing TFSI anions can be catalyzed through the addition of $\mathrm{Li}^{+}$cations. We ascribe this catalytic effect to the change in the EDL structure: the $\mathrm{Li}^{+}$cations preferentially adsorb on the electrode surface and drag the TFSI anions with them, facilitating their reduction. The decomposition of the ionic liquid leads to the formation of an SEI layer, which is studied using an electrochemical quartz crystal microbalance.
\end{abstract}

\section{Introduction}

The electrochemical stability of ionic liquid (IL) electrolytes is a crucial factor for their application in electrochemical devices [1]. In general, they are considered to be extremely stable, reaching stability windows of 3-5 $\mathrm{V}$ depending on the IL composition [2]. These attractive properties are being widely exploited in high-energy electrochemical devices such as lithium-based batteries [1]. Reversible plating/stripping of Li has been reported for various ionic liquids [3-5]. In addition, cycling of different electroactive materials has recently been presented [6-8].

The performance of Li-based batteries is mostly determined by the stability and cyclability of Li metal. These features are strongly affected by the existence and properties of the solid electrolyte interface (SEI) that is formed from decomposition products of the electrolyte [9]. Despite the high electrochemical stability of ILs, SEI formation has also been shown to be present in ILs [10]. Howlett et al. [11] investigated in detail the formation of an SEI layer in ILs containing TFSI anions.

* Corresponding author at: Laboratoire de Réactivité et Chimie des Solides, UMR CNRS 7314, UFR des Sciences, 33 rue saint Leu, 80039 Amiens Cedex, France.

E-mail address: claude.guery@u-picardie.fr (C. Guéry).
They found that the resulting SEI is composed mostly of the native $\mathrm{Li}_{2} \mathrm{O}$ layer and decomposition products of the TFSI anion, such as LiF, $\mathrm{Li}_{2} \mathrm{~S}_{2} \mathrm{O}_{4}, \mathrm{LiSO}_{3} \mathrm{CF}_{3}, \mathrm{Li}_{2} \mathrm{NSO}_{2} \mathrm{CF}_{3}$. On the other hand, some reports state that no SEI is formed in ultra-pure ionic liquids [12] and that impurities are responsible for triggering the decomposition of ILs [12,13].

Another important issue in electrochemical devices is the structure of the electrochemical double layer (EDL). It has been proven both theoretically $[14,15]$ and experimentally [16-18] that the IL ions are highly structured and form a layered EDL on electrodes $[17,18]$ which can undergo rearrangement under imposed polarization [16,19-21]. When polarized, the biggest changes within the EDL are observed in the first adjacent layer; the strength of the ion-electrode interactions [16], compactness [18,22], and conformational changes of ions [19] vary greatly within this particular layer. The influence of the EDL structure on the decomposition of the IL and SEI formation has only been mentioned briefly in a few reports $[10,23]$. Consequently, the electrochemical double layer structure effect is not well understood and further research is needed, as stated in a recent review [1]. In this communication, we report the catalytic reduction of TFSI anions caused by the presence of $\mathrm{Li}^{+}$cations in EMImTFSI ionic liquid. We correlate this effect to the change in the EDL structure upon the addition of $\mathrm{Li}^{+}$cations. 


\section{Experimental}

1-Ethyl-3-methylimidazolium bis(trifluoromethane)sulfonimide (EMImTFSI), $\quad N$-buthyl- $N$-methylpyrrolidinium bis(trifluoromethane)sulfonimide (BMPTFSI) ILs (99.9\% pure, $\mathrm{H}_{2} \mathrm{O}<$ $0.005 \%$ ) and the LiTFSI salt used in this study were purchased from Solvionic. The ILs were purified under vacuum at $75{ }^{\circ} \mathrm{C}$ for 2 days prior to being used, so that the final water content was $\sim 6-20 \mathrm{ppm}$ (Karl Fischer measurement). The LiTFSI and $\mathrm{LiClO}_{4}$ salts were dried at $125{ }^{\circ} \mathrm{C}$ under high vacuum for 2 days. All chemicals were handled and stored in an argon-filled glove box $\left(\mathrm{O}_{2}\right.$ and $\left.\mathrm{H}_{2} \mathrm{O}<0.1 \mathrm{ppm}\right)$.

A three-electrode set-up was used for all electrochemical measurements. Four different substrates, a planar platinum electrode $\left(\mathrm{Pt}_{\mathrm{p}}\right) \mathrm{S}=$ $0.020 \mathrm{~cm}^{2}$, platinum wires $\left(\mathrm{Pt}_{\mathrm{w}}\right)$, stainless steel wires $\left(\mathrm{SS}_{\mathrm{w}}\right)$ and planar glassy carbon (GC) $\mathrm{S}=0.071 \mathrm{~cm}^{2}$ were used as working electrodes (WE). The surface area of the wire-type electrodes was estimated from the length of the submerged fraction of the electrode (surface ranging from 0.017 to $0.033 \mathrm{~cm}^{2}$ ). A platinum grid with high surface area $\left(\mathrm{S} \approx 2 \mathrm{~cm}^{2}\right)$ was used as the counter electrode (CE) and Li metal inside a tube with frit as the reference electrode (RE). All potentials are given versus the $\mathrm{Li}^{+} \mid \mathrm{Li}$ redox couple.

EQCM measurements were conducted using a commercial SEIKO microbalance (SEIKO QCA 922) with AT-cut $9 \mathrm{MHz}$ quartz covered with platinum on both sides. The electroactive geometric surface area was $\mathrm{S}=0.196 \mathrm{~cm}^{2}$. The EQCM was calibrated with a CV measurement in $0.05 \mathrm{M}$ solution of AgTFSI in EMImTFSI, at $100{ }^{\circ} \mathrm{C}$, with a $2 \mathrm{mV} \cdot \mathrm{s}^{-1}$ scanning rate.

The XPS measurements were conducted on a K-Alpha from Thermo Fisher Scientific with $\mathrm{Al} \mathrm{K \alpha}$ radiation $(1486.7 \mathrm{eV}$ ) and a dwell time of $50 \mathrm{~ms}$ (high-resolution). The sample was washed copiously with acetonitrile and dried under vacuum at RT prior to the experiment.

The electron affinity (EA) calculations were performed using the Gaussian 09 computational package [24]. The adiabatic calculations of EAs allowed for geometry optimization of the reduced states. Geometries were optimized at the B3LYP/6-31G(d,p) level of theory $[25,26]$, and the ground states were verified by the absence of any imaginary frequencies. Single point energy calculations were performed using B3LYP/ $6-311++G(d, p)$. The solvation effects were captured using an implicit solvation model, CPCM $[27,28]$, where pyridine (dielectric constant $=$ 13) was chosen as the solvent.

\section{Results and discussion}

Fig. 1a represents the electrochemical response of 0.12 M LiTFSI solution in EMImTFSI under Ar atmosphere at room temperature (RT) and at $100{ }^{\circ} \mathrm{C}$. In both cases a reduction signal is observed, at $1.4 \mathrm{~V}$ at RT and $1.7 \mathrm{~V}$ at $100{ }^{\circ} \mathrm{C}$ (red lines), which was not present in the pure ionic liquid (dashed lines). Similar behavior was found on Pt and $\mathrm{Au}$ electrodes in 0.5 M LiTFSI solution by Gasparotto et al. [29]. They attributed the extra peak mainly to the under-potential deposition of $\mathrm{Li}^{+}$, with additional speculation on the possible formation of $\mathrm{Li}-\mathrm{Au}$ alloys. Other reports claimed that an additional reduction process could originate from impurities in the LiTFSI salt which could trigger SEI formation $[30,31]$. However, to the best of our knowledge, the exact nature of this phenomenon is not well understood.

To investigate the origin of the extra reduction peak, we examined the effect of different electrochemical bath components on the shape of the CV curve (Fig. 1). The general shape of the CV curve is not affected by either the concentration of $\mathrm{Li}^{+}$ions $(0.012-1.0 \mathrm{M})$ or a change in lithium salt composition ( $\mathrm{LiTFSI}, \mathrm{LiClO}_{4}$ ) (Fig. 1b). These results suggest that impurities related to the LiTFSI salt are not responsible for the reduction peak. On the other hand, on changing the ionic liquid cation from $\mathrm{EMIm}^{+}$to $\mathrm{BMP}^{+}$, the reduction at $1.4 \mathrm{~V}$ appeared with a current density 5 times lower than before (Fig. 1c). Furthermore, changing the WE substrate from Pt to $\mathrm{SS}_{\mathrm{w}}$ caused the reduction peak to shift to lower potentials $(1.1 \mathrm{~V})$, while on the GC electrode, the reduction was not visible

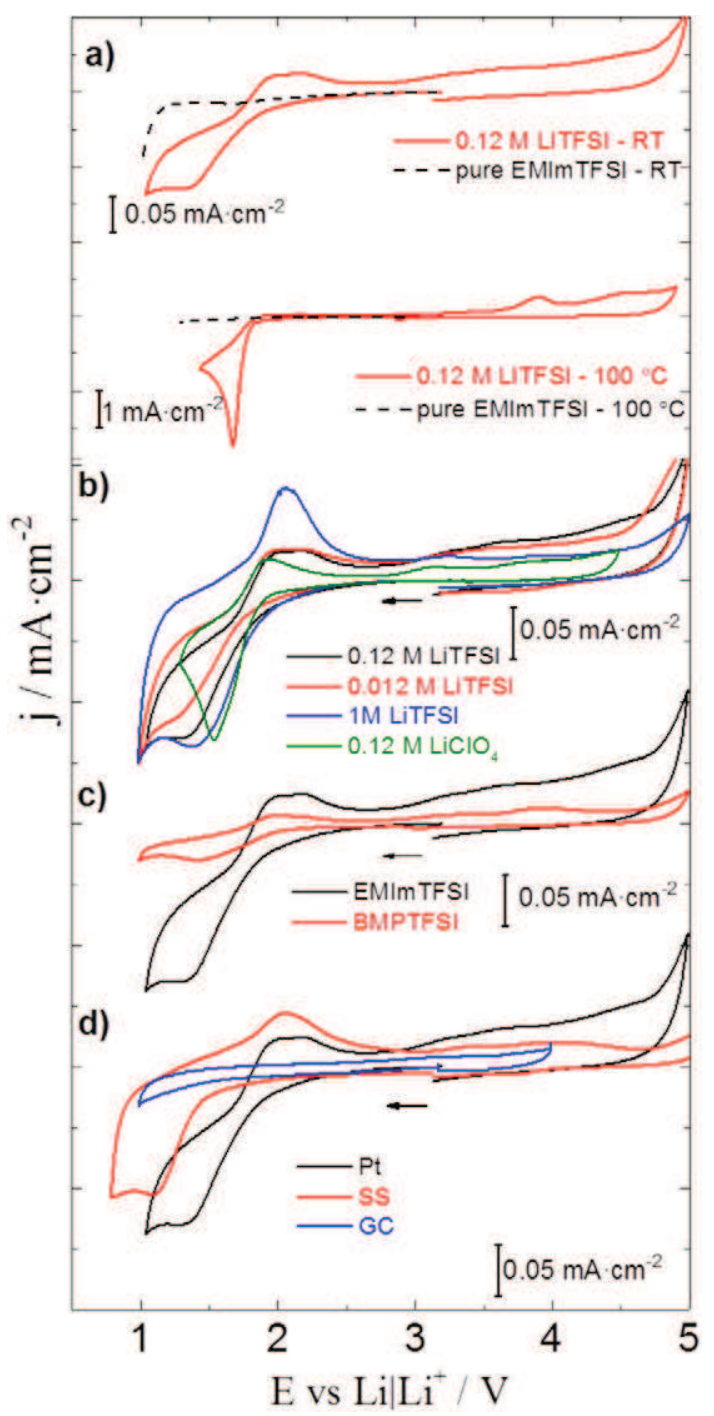

Fig. 1. a) The CV of pure EMImTFSI and $0.12 \mathrm{M}$ LiTFSI solutions at RT (top curves) and $100{ }^{\circ} \mathrm{C}$ (bottom curves). The $\mathrm{CV}$ s of electrolyte containing $\mathrm{Li}^{+}$cations at $\mathrm{RT}$ b) different salt concentrations and salt anion WE - Pt $t_{p}$ c) 0.12 M LiTFSI solution in different ILs, WE $\mathrm{Pt}_{\mathrm{w}}$ d) $0.12 \mathrm{M}$ LiTFSI solution in EMImTFSI on different electrodes. CE - Pt, RE $\mathrm{Ag} \mid \mathrm{Ag}_{2} \mathrm{O}, \mathrm{sr}=50 \mathrm{mV} \cdot \mathrm{s}^{-1}$.

within the chosen potential range (Fig. 1d). The strong dependence on the electrode material and the ionic liquid cation suggests either an alloying reaction or ionic liquid decomposition (SEI formation).

To probe the nature of the reduction process, EQCM studies were performed in $0.12 \mathrm{M}$ LiTFSI solution at $100{ }^{\circ} \mathrm{C}$ under Ar atmosphere on platinum-covered quartz. The experiment was performed at a high temperature in order to decrease frequency noise (due to high viscosity at RT) and to increase the reduction rate. A chronoamperometric experiment at a fixed potential of $1.6 \mathrm{~V}$ was carried out to probe the nature of the electrochemical process and its evolution with time; current and quartz crystal frequency and motional resistance were recorded simultaneously (Fig. 2). At the beginning of the reduction process, a significant decrease in frequency was observed (Fig. 2a) followed by stabilization after $4000 \mathrm{~s}$. In contrast, the motional resistance remained unchanged (Fig. 2b), indicating that the frequency decrease can be attributed to a mass increase at the electrode surface. Based on Sauerbrey's eq. [32] and Faraday's law of electrolysis we calculated the equivalent weight of the deposited compound $(M / z)$ (Fig. 2b). The calculated $M / z$ values stabilized at around $15 \mathrm{~g} \cdot \mathrm{mol}^{-1}$ after $600 \mathrm{~s}$ of the reduction process. The obtained $M / z$ is twice the theoretical value for all possible products of Li-Pt alloy formation [29] or UPD of lithium [29], 


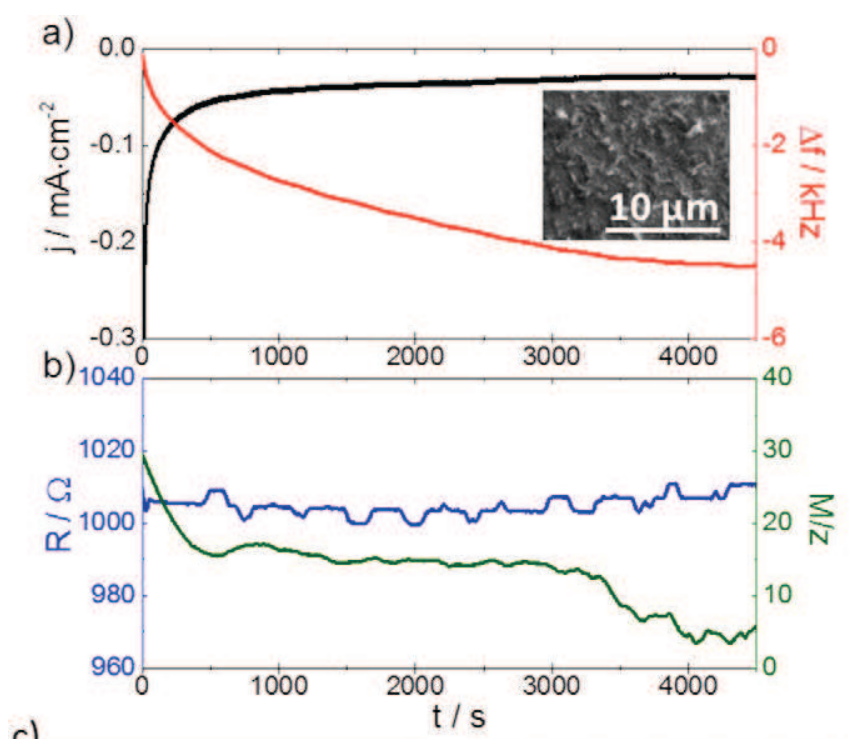

c)
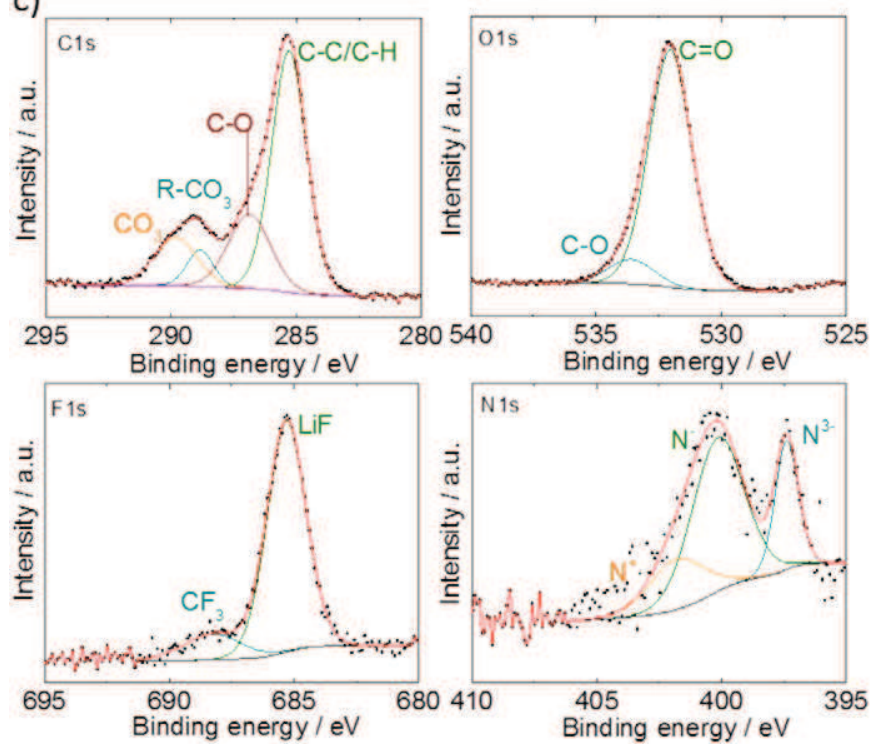

Fig. 2. Potentiostatic EQCM measurements at $1.6 \mathrm{~V}$ vs $\mathrm{Li}_{\mid} \mid \mathrm{Li}^{+}$a) current density and quartz frequency change versus time, the inset represents the SEM images of the deposit. b) quartz motional resistance and calculated $M / z$ values versus time. $0.12 \mathrm{M} \mathrm{LiTFSI}, T=$ $100{ }^{\circ} \mathrm{C}, \mathrm{WE}-\mathrm{Pt}$ mirror polished on quartz, CE - Pt, RE - Ag|Ag $\left.\mathrm{Ag}_{2} \mathrm{c}\right) \mathrm{C} 1 \mathrm{~s}, \mathrm{O} 1 \mathrm{~s}, \mathrm{~F} 1 \mathrm{~s}, \mathrm{~N}$ $1 \mathrm{~s}$ XPS spectra of the SEI layer obtained by potentiostatic deposition at $1.6 \mathrm{~V} \mathrm{vs} \mathrm{Li} \mid \mathrm{Li}^{+}$ for $1 \mathrm{~h}$ over $\mathrm{Pt}_{\mathrm{w}}$ electrode. The deposit was washed copiously with dry acetonitrile and dried under vacuum prior to measurement. $T=100^{\circ} \mathrm{C}, \mathrm{CE}-\mathrm{Pt}, \mathrm{RE}-\mathrm{Ag} \mid \mathrm{Ag}_{2} \mathrm{O}, \mathrm{WE}-\mathrm{Pt}_{\mathrm{w}}$.

see Table 1 . Additionally, considering that the Pt electrochemical alloying process takes place at potentials lower than $0.5 \mathrm{~V} \mathrm{vs} \mathrm{Li}^{\mid} \mathrm{Li}^{+}$ [33] and that the total frequency change of $4 \mathrm{kHz}$ would result in multi-layer Li deposition, alloying and UPD processes are highly unlikely. The formation of $\mathrm{LiOH}$ and $\mathrm{Li}_{2} \mathrm{O}$ due to $\mathrm{O}_{2}$ reduction can also be ruled out, as our ionic liquid was highly pure and the measurement was

Table 1

The $M / z$ values of the possible deposition products, the first column specifies the reduced compound.

\begin{tabular}{llllllllll}
\hline $\begin{array}{l}\text { Reduced } \\
\text { species }\end{array}$ & $\begin{array}{l}\mathrm{UPD} \\
\mathrm{Li}\end{array}$ & $\mathrm{Pt}-\mathrm{Li}$ & $\mathrm{LiOH}$ & $\mathrm{Li}_{2} \mathrm{O}_{2}$ & $\mathrm{Li}_{2} \mathrm{O}$ & $\mathrm{LiF}$ & $\mathrm{Li}_{2} \mathrm{~S}$ & $\mathrm{Li}_{2} \mathrm{CO}_{3}$ & $\mathrm{Li}_{2} \mathrm{~S}_{2} \mathrm{O}_{4}$ \\
\hline $\mathrm{Li}^{+}$reduction & 7 & 7 & - & - & - & - & - & - & - \\
$\mathrm{H}_{2} \mathrm{O}_{\text {impurity }}$ & - & - & 24 & - & - & - & - & - & - \\
$\mathrm{O}_{2 \text { impurity }}$ & - & - & - & 23 & 15 & - & - & - & - \\
$\mathrm{TFSI}^{-\mathrm{a}}$ & - & - & - & - & $30 / z$ & $25 / z$ & $46 / z$ & $74 / z$ & $142 / z$ \\
\hline
\end{tabular}

a The $z$ value of the compounds coming from the IL degradation (SEI formation) is unknown. carried under a protective argon atmosphere. The remaining possibility is decomposition of the ionic liquid. Indeed, SEM image revealed the presence of an irregular SEI layer (Fig. 2a inset). The XPS spectra (Fig. 2c) indicate that the layer was composed mainly of $\mathrm{Li}_{2} \mathrm{CO}_{3}$, lithium alkyl carbonates and LiF. The presence of fluorine implies the breakdown of TFSI anions, which has previously been reported on a Li surface in contact with TFSI-based ILs [10]. Indeed, the N $1 \mathrm{~s}$ spectra showed small quantities of compounds containing negatively charged nitrogen atoms $\left(\mathrm{N}^{-}\right.$and $\mathrm{N}^{3-}$ ), while the $\mathrm{S} 2 \mathrm{p}$ spectra (not shown here) revealed the existence of sulfur compounds at different oxidation states, in agreement with previous studies [10]. The $M / z$ values of possible decomposition products of the TFSI anion are listed in Table 1. Assuming a oneelectron process, the $M / z$ values are very high compared to the measured values, suggesting a multi-electron process $(z>1)$ [10]. Nevertheless, the very small value of $M / z$ indicates that the deposit is mostly composed of light compounds such as $\mathrm{LiF}, \mathrm{Li}_{2} \mathrm{CO}_{3}, \mathrm{Li}_{2} \mathrm{~S}$, which is consistent with the XPS spectra. The scenario of TFSI anion decomposition is supported by the CV curves in BMPTFSI and EMImTFSI baths (i.e. containing the same anion), where the reduction signal at $1.4 \mathrm{~V}$ was present. The difference in reduction peak intensity (very low for BMPTFSI) could be due to stronger adsorption of pyrrolidinium cations at the electrode surface, which diminishes the access of the TFSI anions [34,35]. The stronger BMP cation adsorption may be due either to its greater flexibility, which allows the cation to adopt a flatter surface conformation, and/or to the longer alkyl groups that may favor structuring of the IL, as suggested by Atkin et al. [34]. Moreover, in the case of the BMP cation, the positive charge is more localized than in the EMIm cation, where the charge is delocalized over the aromatic ring. The resulting SEI layer seems to be stable at low potentials, preventing further IL decomposition, as indicated by stabilization of the frequency after $4000 \mathrm{~s}$ (Fig. 2a).

Combined EQCM and CV experiments suggest that the reduction signal in the presence of lithium salt is due to TFSI anion decomposition. However, the role of the lithium salt in this process is not clear. It was recently reported by Lahiri et al. [36] that the addition of $\mathrm{Li}^{+}$to ionic liquids drastically changes the structure of the electrochemical double layer. They suggested that $\mathrm{Li}^{+}$, as a very small cation with a highly localized charge, can adsorb at the electrode in its complexed form $\left[\mathrm{Li}(\mathrm{TFSI})_{\mathrm{x}}\right]^{1-\mathrm{x}}$ to efficiently counter the electrode's negative charge (reduction sweep). A schematic representation of the EDL structure is

\section{Proposed EDL structure under negative polarization}

\section{Pure EMImTFSI}
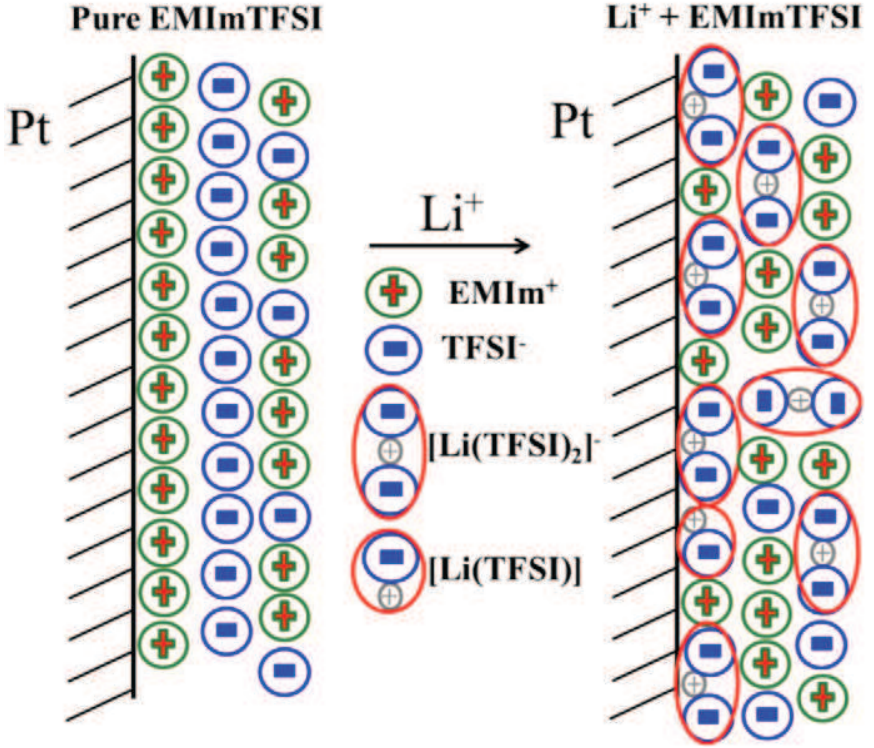

Fig. 3. The proposed schematic of EDL structure at negative polarization in pure ILs and after the addition of $\mathrm{Li}^{+}$cations. 
shown in Fig. 3. As $\mathrm{Li}^{+}$is coordinated by two TFSI anions, [Li(TFSI $\left.)_{2}\right]^{-}$ [37], the adsorption of coordinated $\mathrm{Li}^{+}$(either with two anions or partially dissociated with one TFSI anion) causes an increase in TFSI anion concentration at the electrode surface that may facilitate its breakdown (reduction). In the case of a pure ionic liquid, the adjacent layer is composed almost solely of large cations [38] which block access to the electrode for the TFSI anions. The reduction process is thus suppressed and no reduction peak is visible.

The enhanced reduction of the TFSI anion has not been reported in organic electrolytes with a low concentration of LiTFSI, where instead a severe solvent decomposition usually occurs [39]. However, the situation drastically changes when highly concentrated electrolytes are utilized [39-47]. In such cases, the formation of a structured network of $\mathrm{Li}^{+}$and TFSI anions has been reported $[41,46,47]$, which facilitates reduction of the TFSI anion due to the lower energy of the TFSI LUMO levels. Additionally, an extra reduction signal is generally observed at around $1.5 \mathrm{~V}$ vs $\mathrm{Li} \mid \mathrm{Li}^{+}$due to TFSI anion decomposition, leading to the formation of a stable SEI $[39,40,42-45]$, as in our case. We think that, in ionic liquids where a structured network of anions and cations exists, the reduction of TFSI anions can be facilitated as well. Additionally, the stability of the TFSI anion could be potentially altered by complexation with $\mathrm{Li}^{+}$[47]. Our preliminary DFT adiabatic and vertical electron affinity calculations suggested that the TFSI anion in its complexed form $\left(E A_{\text {adiabatic }}=-3.52 \mathrm{eV}, \mathrm{EA}_{\text {vertical }}=-0.58 \mathrm{eV}\right)$ is more prone to reduction than the naked TFSI anion $\left(\mathrm{EA}_{\text {adiabatic }}=-2.91 \mathrm{eV}, \mathrm{EA}_{\text {vertical }}=\right.$ $-0.09 \mathrm{eV})$ in a medium with a low dielectric constant $(\varepsilon=13)$, as indicated by its lower electron affinity. Nevertheless, despite the higher reactivity of TFSI in ionic liquids, the access of TFSI anions to an electrode can be restricted by strongly adsorbed cations which limit their reduction. The situation changes when $\mathrm{Li}^{+}$cations are introduced as this leads to EDL reconstruction and enhanced TFSI anion decomposition.

\section{Conclusions}

In summary, we have probed the electrochemical behavior of a LiTFSI solution in EMImTFSI-based ionic liquid. An extra reduction peak was found at a potential of $1.4 \mathrm{~V}$ vs $\mathrm{Li} \mid \mathrm{Li}^{+}$when lithium cations were present in the solution. Based on the CV, EQCM and EDX data, we ascribe the extra peak to the breakdown of TFSI anions. This reaction is catalyzed by $\mathrm{Li}^{+}$cations due to induced changes within the double layer. Decomposition of the TFSI anion led to the formation of a stable SEI layer - such layers are crucial for a long cycle life in Li-ion and Limetal based batteries. Our findings give a better understanding of how a SEI layer is formed in TFSI-based ionic liquid solutions. We believe that this new concept of SEI formation will be useful in designing new systems with improved SEI properties and battery performance, by tailoring the $\mathrm{Li}^{+}$-anion interactions.

\section{Acknowledgment}

The authors thank to ALISTORE European Research Institute (FR CNRS 3104) for the financial support to conduct the research. We also would like to thank Shuting Feng for help in DFT calculations and acknowledge Samsung Advanced Institute of Technology (SAIT) for funding her research.

\section{References}

[1] D.R. MacFarlane, N. Tachikawa, M. Forsyth, J.M. Pringle, P.C. Howlett, G.D. Elliott, J.H Davis, M. Watanabe, P. Simon, C.A. Angell, Energy applications of ionic liquids, Energy Environ. Sci. 7 (2014) 232-250.

[2] E.I. Rogers, B. Sljukic, C. Hardacre, R.G. Compton, Electrochemistry in room-temperature ionic liquids: potential windows at mercury electrodes, J. Chem. Eng. Data 54 (2009) 2049-2053.

[3] L. Grande, E. Paillard, G.-T. Kim, S. Monaco, S. Passerini, Ionic liquid electrolytes for Li-air batteries: lithium metal cycling, Int. J. Mol. Sci. 15 (2014) 8122-8137.
[4] A. Fernicola, F. Croce, B. Scrosati, T. Watanabe, H. Ohno, LiTFSI-BEPyTFSI as an improved ionic liquid electrolyte for rechargeable lithium batteries, J. Power Sources 174 (2007) 342-348.

[5] H. Yoon, P.C. Howlett, A.S. Best, M. Forsyth, D.R. MacFarlane, Fast charge/discharge of Li metal batteries using an ionic liquid electrolyte, J. Electrochem. Soc. 160 (2013) A1629-A1637.

[6] J. Li, S. Jeong, R. Kloepsch, M. Winter, S. Passerini, Improved electrochemical performance of LiMO2 ( $\mathrm{M}=\mathrm{Mn}, \mathrm{Ni}, \mathrm{Co})$-Li2MnO3 cathode materials in ionic liquid-based electrolyte, J. Power Sources 239 (2013) 490-495.

[7] L. Xue, K. Ueno, S.-Y. Lee, C.A. Angell, Enhanced performance of sulfone-based electrolytes at lithium ion battery electrodes, including the LiNi0.5Mn1.504 high voltage cathode, J. Power Sources 262 (2014) 123-128.

[8] L.N. Wang, H.R. Byon, N-Methyl- $N$-propylpiperidinium bis(trifluoromethanesulfonyl)imide-based organic electrolyte for high performance lithium-sulfur batteries, J. Power Sources 236 (2013) 207-214.

[9] X.-B. Cheng, R. Zhang, C.-Z. Zhao, F. Wei, J.-G. Zhang, Q. Zhang, A review of solid electrolyte interphases on lithium metal anode, Adv. Sci. 3 (2015) 1500213-1500233.

[10] D.R. MacFarlane, J.M. Pringle, P.C. Howlett, M. Forsyth, Ionic liquids and reactions at the electrochemical interface, Phys. Chem. Chem. Phys. 12 (2010) 1659-1669.

[11] P.C. Howlett, N. Brack, A.F. Hollenkamp, M. Forsyth, D.R. MacFarlane, Characterization of the lithium surface in $N$-methyl- $N$-alkylpyrrolidinium bis(trifluoromethanesulfonyl)amide room-temperature ionic liquid electrolytes, J. Electrochem. Soc. 153 (2006) A595.

[12] F. Endres, S.Z. El Abedin, N. Borissenko, Probing lithium and alumina impurities in air- and water stable ionic liquids by cyclic voltammetry and in-situ scanning tunneling microscopy, Z. Phys. Chem. 220 (2006) 1377-1394.

[13] S. Randström, M. Montanino, G.B. Appetecchi, C. Lagergren, A. Moreno, S. Passerini, Effect of water and oxygen traces on the cathodic stability of $\mathrm{N}$-alkyl- $\mathrm{N}$ methylpyrrolidinium bis(trifluoromethanesulfonyl)imide, Electrochim. Acta 53 (2008) 6397-6401.

[14] J. Vatamanu, L. Xing, W. Li, D. Bedrov, Influence of temperature on the capacitance of ionic liquid electrolytes on charged surfaces, Phys. Chem. Chem. Phys. 16 (2014) 5174-5182.

[15] M.V. Fedorov, A.A. Kornyshev, Ionic liquids at electrified interfaces, Chem. Rev. 114 (2014) 2978-3036.

[16] R. Atkin, N. Borisenko, M. Drüschler, S. Zein El Abedin, F. Endres, R. Hayes, B. Huber, B. Roling, An in situ STM/AFM and impedance spectroscopy study of the extremely pure 1-butyl-1-methylpyrrolidinium tris(pentafluoroethyl)trifluorophosphate/ $\mathrm{Au}(111)$ interface: potential dependent solvation layers and the herringbone reconstruction, Phys. Chem. Chem. Phys. 13 (2011) 6849-6857.

[17] T. Carstens, R. Hayes, S. Zein El Abedin, B. Corr, G.B. Webber, N. Borisenko, R. Atkin, F. Endres, In situ STM, AFM and DTS study of the interface 1-hexyl-3methylimidazolium tris(pentafluoroethyl)trifluorophosphate/Au(111), Electrochim. Acta 82 (2012) 48-59.

[18] T.A. Petach, A. Mehta, R. Marks, B. Johnson, M.F. Toney, D. Goldhaber-Gordon, Voltage-controlled interfacial layering in an ionic liquid on $\mathrm{SrTiO}_{3}$, ACS Nano 10 (2016) 4565-4569.

[19] S. Baldelli, Surface structure at the ionic liquid-electrified metal interface, Acc. Chem. Res. 41 (2008) 421-431.

[20] J. Vatamanu, O. Borodin, G.D. Smith, Molecular insight into the potential and temperature dependence of the differential capacitance of a room-temperature ionic liquid at graphite electrodes, J. Am. Chem. Soc. 132 (2010) 14825-14833.

[21] E. Paek, A.J. Pak, G.S. Hwang, A computational study of the interfacial structure and capacitance of graphene in [BMIM][PF6] ionic liquid, J. Electrochem. Soc. 160 (2013) A1-A10.

[22] J. Vatamanu, O. Borodin, D. Bedrov, G.D. Smith, Molecular dynamics simulation study of the interfacial structure and differential capacitance of alkylimidazolium bis(trifluoromethanesulfonyl)imide [Cnmim][TFSI] ionic liquids at graphite electrodes, J. Phys. Chem. C 116 (2012) 7940-7951.

[23] M. Yamagata, N. Nishigaki, S. Nishishita, Y Matsui, T. Sugimoto, M. Kikuta, T. Higashizaki, M. Kono, M. Ishikawa, Charge-discharge behavior of graphite negative electrodes in bis(fluorosulfonyl)imide-based ionic liquid and structural aspects of their electrode/electrolyte interfaces, Electrochim. Acta 110 (2013) 181-190.

[24] M.J. Frisch, G.W. Trucks, H.B. Schlegel, G.E. Scuseria, M.A. Robb, J.R. Cheeseman, G Scalmani, V. Barone, G.A. Petersson, H. Nakatsuji, X. Li, M. Caricato, A. Marenich, J. Bloino, B.G. Janesko, R. Gomperts, B. Mennucci, H.P. Hratchian, J.V. Ortiz, A.F Izmaylov, J.L. Sonnenberg, D. Williams-Young, F. Ding, F. Lipparini, F. Egidi, J. Goings, B. Peng, A. Petrone, T. Henderson, D. Ranasinghe, V.G. Zakrzewski, J. Gao, N. Rega, G. Zheng, W. Liang, M. Hada, M. Ehara, K. Toyota, R. Fukuda, J. Hasegawa, M. Ishida, T. Nakajima, Y. Honda, O. Kitao, H. Nakai, T. Vreven, K. Throssell, J.A. Montgomery, J.E. Peralta, F. Ogliaro, M. Bearpark, J.J. Heyd, E. Brothers, K.N. Kudin, V.N. Staroverov, T. Keith, R. Kobayashi, J. Normand, K. Raghavachari, A. Rendell, J.C. Burant, S.S. Iyengar, J. Tomasi, M. Cossi, J.M. Millam, M. Klene, C. Adamo, R. Cammi, J.W. Ochterski, R.L Martin, K. Morokuma, O. Farkas, J.B. Foresman, D.J. Fox, Gaussian 09, Revision A.02, Gaussian, Inc., Wallingford CT, 2016.

[25] C.T. Lee, W.T. Yang, R.G. Parr, Development of the Colle-Salvetti correlation-energy formula into a functional of the electron-density, Phys. Rev. B 37 (1988) 785-789.

[26] A.D. Becke, Density-functional thermochemistry. 3. The role of exact exchange, J. Chem. Phys. 98 (1993) 5648-5652.

[27] V. Barone, M. Cossi, Quantum calculation of molecular energies and energy gradients in solution by a conductor solvent model, J. Phys. Chem. A 102 (1998 1995-2001.

[28] M. Cossi, N. Rega, G. Scalmani, V. Barone, Energies, structures, and electronic properties of molecules in solution with the C-PCM solvation model, J. Comput. Chem. 24 (2003) 669-681. 
[29] L.H.S. Gasparotto, N. Borisenko, N. Bocchi, S. Zein El Abedin, F. Endres, In situ STM investigation of the lithium underpotential deposition on $\mathrm{Au}(111)$ in the air- and water-stable ionic liquid 1-butyl-1-methylpyrrolidinium bis(trifluoromethylsulfonyl)amide, Phys. Chem. Chem. Phys. 11 (2009) 11140.

[30] E. Paillard, Q. Zhou, W.A. Henderson, G.B. Appetecchi, M. Montanino, S. Passerini, Electrochemical and physicochemical properties of PY[sub 14]FSI-based electrolytes with LiFSI, J. Electrochem. Soc. 156 (2009) A891.

[31] G.B. Appetecchi, M. Montanino, A. Balducci, S.F. Lux, M. Winterb, S. Passerini, Lithium insertion in graphite from ternary ionic liquid-lithium salt electrolytes: I. Electrochemical characterization of the electrolytes, J. Power Sources 192 (2009) 599-605.

[32] G. Sauerbrey, Verwendung von Schwingquarzen zur Wagung Dunner Schichten und zur Mikrowagung, Z. Phys. 155 (1959) 206-222.

[33] S.H. Park, J. Winnick, P.A. Kohl, Investigation of the lithium couple on Pt, Al, and $\mathrm{Hg}$ electrodes in lithium imide-ethyl methyl sulfone, J. Electrochem. Soc. 149 (2002) A1196.

[34] R. Atkin, S.Z. El Abedin, R. Hayes, L.H.S. Gasparotto, N. Borisenko, F. Endres, AFM and STM studies on the surface interaction of [BMP]TFSA and [EMIm] TFSA Iionic liquids with Au(111), J. Phys. Chem. C 113 (2009) 13266-13272.

[35] R. Hayes, N. Borisenko, M.K. Tam, P.C. Howlett, F. Endres, R. Atkin, Double layer structure of ionic liquids at the $\mathrm{Au}(111)$ electrode interface: an atomic force microscopy investigation, J. Phys. Chem. C 115 (2011) 6855-6863.

[36] A. Lahiri, T. Carstens, R. Atkin, N. Borisenko, F. Endres, In situ atomic force microscopic studies of the interfacial multilayer nanostructure of LiTFSI-Py-1,Py-4 TFS on $\mathrm{Au}(111)$ : influence of $\mathrm{Li}+$ ion concentration on the $\mathrm{Au}(111) / \mathrm{IL}$ interface, J. Phys. Chem. C 119 (2015) 16734-16742.

[37] J.-C. Lassègues, J. Grondin, C. Aupetit, P. Johansson, Spectroscopic identification of the lithium ion transporting species in LiTFSI-doped ionic liquids, J. Phys. Chem. A 113 (2009) 305-314.
[38] Z.Z. Hu, J. Vatamanu, O. Borodin, D. Bedrov, A comparative study of alkylimidazolium room temperature ionic liquids with FSI and TFSI anions near charged electrodes, Electrochim. Acta 145 (2014) 40-52.

[39] Y. Pan, G. Wang, B.L. Lucht, Cycling performance and surface analysis of lithium bis(trifluoromethanesulfonyl)imide in propylene carbonate with graphite, Electrochim. Acta 217 (2016) 269-273.

[40] L. Suo, Y.-S. Hu, H. Li, M. Armand, L. Chen, A new class of solvent-in-salt electrolyte for high-energy rechargeable metallic lithium batteries, Nat. Commun. 4 (2013) 1481.

[41] Y. Yamada, K. Furukawa, K. Sodeyama, K. Kikuchi, M. Yaegashi, Y. Tateyama, A Yamada, Unusual stability of acetonitrile-based superconcentrated electrolytes for fast-charging lithium-ion batteries, J. Am. Chem. Soc. 136 (2014) 5039-5046.

[42] X.-R. Liu, L. Wang, L.-J. Wan, D. Wang, In situ observation of electrolyte-concentration-dependent solid electrolyte interphase on graphite in dimethyl sulfoxide, ACS Appl. Mater. Interfaces 7 (2015) 9573-9580.

[43] Y. Yamada, A. Yamada, Review-superconcentrated electrolytes for lithium batteries, J. Electrochem. Soc. 162 (2015) A2406-A2423.

[44] K. Fujii, H. Wakamatsu, Y. Todorov, N. Yoshimoto, M. Morita, Structural and electrochemical properties of $\mathrm{Li}$ ion solvation complexes in the salt-concentrated electrolytes using an aprotic donor solvent $\mathrm{N}, \mathrm{N}$-dimethylformamide, J. Phys. Chem. C 120 (2016) 17196-17204.

[45] M.L. He, Kah Chun, X. Ren, N. Xiao, W.D. McCulloch, L.A. Curtiss, Y. Wu, Concentrated electrolyte for the sodium-oxygen battery: solvation structure and improved cycle life, Angew. Chem. Int. Ed. 55 (2016) 15310-15314.

[46] LE Camacho-Forero, T.W. Smith, P.B. Balbuena, Effects of high and low salt concentration in electrolytes at lithium-metal anode surfaces, J. Phys. Chem. C 121 (2017) 182-194.

[47] K. Sodeyama, Y. Yamada, K. Aikawa, A. Yamada, Y. Tateyama, Sacrificial anion reduction mechanism for electrochemical stability improvement in highly concentrated Li-salt electrolyte, J. Phys. Chem. C 118 (2014) 14091-14097. 